\title{
Financial support by older adults to family members: a configurational perspective
}

\author{
Marie Baeriswyl ${ }^{1,2 *}$ (D), Myriam Girardin ${ }^{1,2}$ and Michel Oris ${ }^{1,2,3}$ \\ ${ }^{1}$ Swiss National Centre of Competence in Research LIVES-Overcoming Vulnerability: Life Course \\ Perspectives (NCCR LIVES), University of Geneva, Geneva, Switzerland, ${ }^{2}$ Centre for the Interdisciplinary \\ Study of Gerontology and Vulnerability (CIGEV), University of Geneva, Geneva, Switzerland and ${ }^{3}$ Institute \\ of Demography and Socioeconomics, University of Geneva, Geneva, Switzerland \\ *Corresponding author. E-mail: marie.baeriswyl@unige.ch
}

(Received 14 July 2020; revised 9 July 2021; accepted 9 July 2021; first published online 18 August 2021)

\begin{abstract}
Most research on financial inter vivos transfers from older parents to their family members is focused on the giver-receiver dyad, usually between an older parent and an adult child. This study aimed to investigate older adults' financial support beyond this level of intergenerational dyads using an egocentric network perspective (i.e., the configurational approach). Data were from a sample of 2,991 older adults (aged 65 and older) from the Vivre/Leben/Vivere study, a large survey addressing family life and health conditions of older people in Switzerland. We used Wald tests and regression analyses to identify how financial transfers are related to family network properties in later life. Findings showed that older parents' propensity to provide financial support is associated with the density of practical help exchanges within the family (mainly for men) and with the position (mainly for women) and the role they play within their family configuration.
\end{abstract}

Keywords: Conflict; family configuration; financial support; older adults; practical help

\section{Introduction}

Older adults are important support providers within their family network [Baeriswyl (2016); Girardin (2017)]. One of the several dimensions of support is financial. Given that the socioeconomic position of the older adults significantly improved in the second half of the 20th century, along with the development of retirement systems and economic growth [Oris et al. (2017)], older parents are more frequently in positions to financially support family members, particularly their children [Kohli (1999)]. Indeed, children and, generally, the offspring are the main beneficiaries of financial transfers within the family [Attias-Donfut et al. (2005); Albertini et al. (2007); Swartz (2009); Attias-Donfut and Litwin (2015)]. Intergenerational transfer of

(C) Université catholique de Louvain 2021. This is an Open Access article, distributed under the terms of the Creative Commons Attribution-NonCommercial-NoDerivatives licence (http://creativecommons.org/licenses/by-nc-nd/4.0/), which permits non-commercial re-use, distribution, and reproduction in any medium, provided the original work is unaltered and is properly cited. The written permission of Cambridge University Press must be obtained for commercial re-use or in order to create a derivative work. 
money from older parents to adult children constitutes important support for the younger generations, particularly because the transition to adulthood in most European countries has become quite uneasy, and less linear in the last decades [Brückner and Mayer (2005); Buchmann and Kriesi (2011)]. Children, for instance, may benefit from parental help to purchase real property, deal with the cost of childbirth, and face disruptive events such as unemployment or divorce [Kohli and Albertini (2008); Le Goff et al. (2017)]. Typically, transfers of money within the family function as informal insurances and complete the pillars of the welfare state [Kohli (2004)].

In this perspective, we consider inter vivos gifts (i.e., transfers between living family members) separate from inheritance and bequests as shown in the literature. Whereas a legal framework frames inheritance and bequest, inter vivos gifts from an older parent to family members directly depend on internal family logics and functioning [Kohli and Künemund (2003)]. Unlike inheritance, inter vivos financial transfers are not equally distributed within the family: They are most likely to be given by the older parents to the family member that needs it the most. In this context, they tend to level inequalities within the family [Kohli and Künemund (2003); Kohli (2004); Künemund et al. (2005)].

However, to understand financial support within the family, most studies focused on the giver-receiver dyad, describing the profile of the giver or the receiver, or the relationship between them. Relational dynamics in larger family context have been ignored so far. This is the reason we proposed studying financial transfers using the configurational approach [Elias (1991); Widmer (2016)]. The main assumption of this approach is that key family dyads such as the parent-child are embedded within a complex network of both supportive and/or tense family ties that influence how these dyads develop. Simultaneously, dyadic relationships, which might also be both supportive and/or tensed, influence how the family network is shaped and organized. The influence is thus bidirectional [Widmer and Jallinoja (2008); Castrén and Ketokivi (2015)].

Using a representative sample of older adults living in Switzerland, this article explores how financial transfers from older parents to their family members living outside of the household are related to the relational dynamics of their larger family configuration. We considered patterns of practical help exchanges and conflict in larger family networks, which are both fundamental dimensions of family relationships [van Gaalen and Dyskstra (2006); Thoits (2011)]. Given the gender differences in the family network's dynamics [Cornwell (2011); Girardin and Widmer (2015)], we have a special interest in the extent to which women and men differ in providing financial support to their family members according to their family network properties.

In the following pages, the research literature on dyadic financial transfers is addressed, focusing on the main factors that are usually propounded to explain this supportive relationship. On this basis, we demonstrate the originality of our approach that explores the understudied meso level of family networks, while developing its main theoretical issues, on which we have built a set of hypotheses regarding family network properties and financial transfers from older parents to their family members. Thereafter, we discuss the data and method by which we have established our empirical analyses. Results show the extent financial support from older parents to family members is related to various family network properties and the extent these links depend on gendered logics. A final discussion underlines the fact that the relational issues of dyadic financial transfers need to be considered within the larger context of family configurations in which they are embedded to be fully understood. 


\section{Literature review}

\subsection{Patterns of dyadic financial support}

To account for dyadic financial transfers, most studies focused either on the givers' and/ or on the recipients' characteristics [Kohli (1999, 2004); Kohli and Künemund (2003); Albertini et al. (2007)]. Socioeconomic factors such as older parents' education, income, occupational status, and health contribute to explaining financial support within the family [Kohli (1999); Kohli and Künemund (2003); Albertini et al. (2007)]. The allocated amount depends on the older parents' social status: When they are wealthier, the provided support is higher [Albertini and Radl (2012)]. Regarding the recipients, the lack of money is a crucial factor [Kohli (2004)].

The age of older parents is another well-documented factor. Overall, giving practical help-such as caring for grandchildren-decreases with aging and health issues [Armi Cholley et al. (2008)]. In this context, financial support appears to be less dependent on the older parent's health status than most other types of support that are more physically demanding. However, financial transfers from older parents to adult children decline with age [Albertini et al. (2007)]. One possible explanation refers to the children's situation. Adult children who are relatively advanced in age are more likely to have a professional position, a stable family and be able to rely on their savings and money. Therefore, they need less financial support from their parents than younger children that are transiting to adulthood [Künemund et al. (2005)].

Another important factor of family support is gender. Although older men and women are both active support providers in the family, they do not give the same types of support [Baeriswyl (2016)]. For financial support, however, the literature provides contrasting results. In some studies, men, who have mainly fulfilled the central economic role of being the breadwinner in the family across their life course, are usually in a better socioeconomic position than women after retirement [Oris et al. (2017)] to provide more financial support to their children than women [Albertini et al. (2007)]. However, in other studies, providing financial support within the family is not influenced by older parents' gender [Kohli $(1999,2004)]$. Some other findings explain those contrasted results. Szydlik (2016) has shown that financial transfers are dependent on the quality of the intergenerational relationship, for instance, in terms of emotional proximity. Older women, due to their greater investment in the family domain, are more likely to develop close relationships with their children than men are; they are more likely to help their children in financial distress [Silverstein et al. (2006)]. Thus, financial support dynamics are not gender-neutral. Further, the motives for giving support vary according to gender. Women are more responsive to the norms of family solidarity; hence, tend to support their family members without necessarily expecting much in return, fostering their financial support within families [Kohli and Künemund (2003); Kohli (2004)].

Research has further highlighted the importance of macro-level factors. Several studies have pointedly focused on the impact of social structures on financial transfers in the family. These researchers investigated the national patterns of such transfers across countries, with a special interest in their socioeconomic systems and social security policies [Kohli (2004); Attias-Donfut et al. (2005); Albertini et al. (2007)]. Results revealed a north-to-south gradient in the European patterns: Financial support is less frequent but more intense in southern welfare state regimes [Ferrera (1996)] and more frequent but less intense in Nordic countries (referring to social-democrat regimes) [Esping-Andersen (1990)]. Continental countries 
(conservative regimes) showed an intermediary position. Countries that are fully illustrative of a liberal vision, such as Great Britain, are absent in these studies. Switzerland, as a mixed model of conservative and liberal regimes, is in an intermediary position in terms of frequency of financial transfers within the family; however, it shows the highest amount of provided financial support to family members, too [Attias-Donfut et al. (2005); Albertini et al. (2007)].

\subsection{Toward a configurational approach of financial transfers}

Focusing either on both the provider and receiver's characteristics (at a micro-level) or on financial transfers within the family across countries (at a macro-level), the literature has rarely explored the family dynamics in which dyadic financial transfers are embedded (at a meso-level). Financial support within the family configuration needs to be further developed. According to the configurational perspective, this particular transfer between two family members cannot be examined as a separate entity as it is part of a network of interdependent ties and exchanges that link the various members within the family configuration. These interdependencies provide diverse types of support and tensions that should be considered to understand financial transfers within family [Widmer (2016)].

More specifically in social gerontology, family is considered as a major source of support, providing emotional and practical help to older parents with declining health [Armi Cholley et al. (2008); Girardin (2017)]. Conversely, older members can be a valuable support to the younger ones who face critical events in their life course and need various resources [Künemund et al. (2005)]. Family additionally raises ambivalence and conflict [Lüscher and Pillemer (1998); Connidis (2015); Girardin et al. (2018)]. Assuredly, provided support generates relational dependency within the family network and creates power and control issues. This situation might be more pronounced in financial transfers, as money is a specific resource, which is related to social power [Bourdieu (1986); Zelizer (2017)]. In such a case, the recipient may experience the supportive relationship as controlling, oppressive, or intrusive [Silverstein et al. (1996); Thoits (2011)]. Consequently, tensions are likely to emerge and spread over the entire family network due to the various ties relating the protagonists with the other family members. Besides, a distribution of resources within the family network that is unequal may generate jealousy and be another source of tension between various members of the family [Widmer (2016)].

Family networks are diverse in the organization of their interdependent ties and exchanges. Research on personal networks emphasizes distinct properties. One is the density of ties within personal networks [Hanneman and Riddle (2005); Broese van Groenou and van Tilburg (2007)]. Density indicates the degree of tightness of interconnections among network members. Each family network is characterized by more or less high densities of both support and conflict. At one extreme, the first type of family networks shows low densities of both support and conflict. In such a type, family members are hardly connected through supportive or tense ties [Girardin et al. (2018)]. At the other extreme, family networks may be characterized by a high density of support and conflict among family members: All network members help each other and conflict with each other. In these networks, supporting members in need is easy and quick to organize due to the close connections between all members of the configuration [Cornwell (2009a, 2009b, 2011); Girardin and Widmer (2015)]. However, the collective support may be associated with social 
control and pressure, creating tensions between family members [Cornwell (2009a, 2009b, 2011)]. Thus, dense family networks are not only a guarantee of collective support but also an important source of conflict and negative valence.

Density is a property of the entire family network. Other indicators focus on the respondents: egos' centrality and egos' role within their family exchanges [Hanneman and Riddle (2005); Broese van Groenou and van Tilburg (2007)]. Egos' centrality refers to the extent the respondents have a central position within their family network. When respondents are central, this means that they control the flow of exchanged resources between the other family members by playing the role of an intermediary within their family configuration [Wasserman and Faust (1994)]. They consequently have a higher autonomy and a greater influence within their personal network [Burt (2001); Granovetter (1973)]. Accordingly, being central gives a certain power to people who are key players within their family configuration [Widmer (2016)]. However, in the case of conflicting ties, being central refers to the extent egos are in active opposition to their family members. Contrary to being central in supportive ties, centrality in conflicting ties is a highly stressful situation [Widmer et al. (2018)].

Egos' role refers to the extent respondents are active in family exchanges. Regarding support, egos may be active in giving support to their family members. Furthermore, they may be active in mobilizing support from their family members. Being active in both roles (i.e., recipient and provider) enables egos to be involved in support exchanges within the family, preventing them from being uniquely debtors or creditors at the network level. Similarly, egos may hold a dominant role in conflict within their family network: On the one hand, egos may upset their family members, while on the other hand, they may be upset by them [Widmer (2016)]. Egos' involvement in family support and/or in conflict varies in form and intensity from case to case.

\subsection{Network properties and financial transfers}

In this section, the potential relationships between network properties and inter vivos transfers of money from older parents to family members are discussed. First, we expect such helps to be related to high densities of both practical help and conflict within the family network. On the one hand, a high density of support may stimulate older parents' financial transfers within their family configuration; in doing so, they are involved in the broader dynamics of family exchanges even at a very old age. On the other hand, older parents' financial support could likewise contribute to boosting support exchanges within family configurations. We equally expect that the older parents' propensity to give money within the family may favor their centrality in the support network. The money giver is indeed a key and powerful actor in exchanges within the family network. Alternatively, holding a central position in family exchanges may foster providing financial support to family members. First, individuals in a central position have better knowledge of the family members in need than the others; they are therefore more prone to allocate money. Second, providing financial support may contribute to maintaining centrality, which is the most influential position within the family network.

Holding an active role in support exchanges fosters the propensity to give money. If older parents play an active role as providers, offering various types of support to many of their family members, it is quite likely that they would be inclined to offer financial support when necessary. In this situation, giving money represents one of the many types of support they can provide. Similarly, being active in the recipient's role 
is likely to be associated with giving financial support. If the older parents affected by health decline receive different types of support from various family members, providing financial support could be useful to maintain balance in support exchanges, allowing egos to remain active members within their family network [Leopold and Raab (2011)]. Alternatively, giving money may stimulate family support through the reciprocity principle [Antonucci and Jackson (1990)] - that is, family members who have received financial support from their older parents are more likely to return them some practical help. In both situations, providing money to family members is associated with greater integration of the older parent within family exchanges.

Using the configurational approach to understand financial transfers within families, it is expected that giving financial help may generate relational dependency between the provider and recipient and be a source of tensions that is likely to spread across the entire family network. The unequal distribution of resources-as it is mainly the case with financial transfers within the family [Kohli and Künemund (2003); Suitor et al. (2006)] - could encourage conflicts between family members as well. Moreover, older parents might upset some family members who feel left out and, in return, be upset by complaining family members. Additionally, the older parents' financial support likely puts them at the center of a conflict network when financial resources are limited and might be perceived as unequally distributed within family configurations. In other words, the older parents may become the target of all frustrations, and thus, centralize tensions from their family members.

Conflict in family relationships could foster financial transfers rather than other types of practical help. Giving money could be used by older parents to decrease conflict density within the family, for instance by balancing socioeconomic inequalities among family members but also to ease existing conflicts directed to themselves, or around themselves when they are in the center of family tensions. Essentially, giving money does not request frequent, face-to-face interactions that could be emotionally costly. These are some reasons financial support might be associated with high conflict density within family networks and with egos' centrality and roles in conflict network.

\subsection{Gender roles within family networks and financial transfers}

We cannot assume that the relationships between network properties and old adults' financial support within their family network are gender-neutral. Egos' gender is a crucial dimension when we come to the properties of family networks [Cornwell (2011); Girardin and Widmer (2015)]. First, due to their role as kin keepers, women are more involved in family life and are consequently more prone than men to provide support in an altruistic manner (i.e., unconditionally) whereas men are more likely to expect support in return [Kohli and Künemund (2003)]. In addition, women's greater involvement in family ties makes them more active and more central than men in support exchanges within their family configuration [Cornwell (2011); Girardin and Widmer (2015)]. Although less central, men tend to be embedded in denser support exchanges than women. Given that they are more likely to be married than women in old age, men can rely on their partner to activate support exchanges within their family configuration [Cornwell (2011)]. Due to their greater involvement in family ties, women are more inclined to face tensions within family networks than men who feel more distant from family strain [Antonucci (2001)].

Based on these studies, the link between network properties and the propensity of an older parent to give financial support within the family differs according to gender. 
Women propensity to give money can be attributable to their active role as support providers and their centrality in support exchanges. Conversely, given that men are less active and less central within family configurations, we hypothesize that men's propensity to give money is more related to the dynamics of support exchanges within their family network. In other words, men more than women are likely to provide financial support when they are embedded in dense family networks. Furthermore, men tend to expect support in return for their family investment more than women do; hence, we postulate that providing financial support is more associated with receiving practical help for men than for women.

Negative ties are equally an important concern. As mentioned above, the allocation of money by an older parent can result in tensions among family members. Tense ties could lead to financial transfers to avoid family breakdown. Since women are more sensitive to family conflicts [Antonucci (2001)], they rather than men would be prone to provide money to ease tensions. Therefore, it is expected that women's propensity to provide financial support is more positively related to conflict density than men's propensity is. For these same reasons, being active and central in a family conflict is more likely to be associated with giving money when the ego is female.

\subsection{Summary}

This paper aims to examine older parents' financial support within the broader and complex network of positive and negative family ties. Specifically, we observe how the propensity of older adults to provide such help is related to the relational dynamics of their family configuration. Following the configurational perspective, we refer to three personal network properties used in social network analysis: density of ties, ego's centrality, and ego's roles as a provider and as a recipient, respectively. These network properties are considered in the perspectives of practical support and conflict, both of which are fundamental dimensions of family relationships [Widmer (1999, 2016); van Gaalen and Dykstra (2006); Thoits (2011)]. Based on the literature discussed in the preceding sections, we made 8 hypotheses, but reduced it to 4 for the sake of clarity:

- H1. Financial transfer is linked to a higher network density of practical help.

- H2. Financial transfer is linked to a higher egos' centrality within practical help exchanges.

- H3. Financial transfer is linked to a higher network density of conflict.

- H4. Financial transfer is linked to a higher egos' centrality within conflicts.

Since men and women in old age differ in the way in which they are embedded and active in their family networks, we expect that the first hypothesis applies only to males and the following three to females.

\section{Methodology}

\subsection{Data and sample}

The data came from the Vivre/Leben/Vivere (VLV) study, which is a large, interdisciplinary survey on the life and health conditions of people aged 65 and above, conducted in 2011/2012 in five cantons of Switzerland (3,659 participants). 
These five regions are representative of the sociocultural diversity of Switzerland on a linguistic, socioeconomic, and political level [Oris et al. (2016)]. The sample was stratified by sex and age groups to guarantee a sufficient number of individuals in each category (typically the oldest men) for robust analyses. VLV data were collected using self-assessed questionnaires and in-home, face-to-face interviews with a standardized interview schedule. Overall, 579 individuals with cognitive impairments were dropped from the initial working sample as they were unable to answer properly. In addition, 89 individuals who failed to provide valid answers for some of the measures used in our analysis were dropped from our working sample, which was finally reduced to 2,991 individuals.

\subsection{Measures}

VLV included a question about the frequency of giving financial support by focal individuals to a non-cohabiting family member. In the face-to-face questionnaire, respondents were asked about a list of services that they could give to family members: "I will list different types of services we can provide to relatives. Concerning family members (excluding those who live with you), can you tell how often you provide these various services by choosing between never, rarely, sometimes and often." One service type was "Giving them financial support". In this question, the term family member was left undefined. The time frame of the given support (e.g., during the last month) was not specified; however, the question was formulated in the present tense, assuming to be current to some extent. We dichotomized this index in distinguishing respondents who never give economic support from all the others $(1=$ gives economic help at least rarely, $0=$ never gives economic help). Indeed, financial transfers do not need to be frequent or even regular to be important for individuals. To better assess the results achieved-as a test of robustness-we considered another threshold of financial transfers, assuming more regularity in providing support $(1=$ gives economic help at least sometimes).

Following the family network method [FNM; Widmer et al. (2013)], we asked respondents - in the face-to-face questionnaire-to list a maximum of five individuals they considered to be significant family members at the time of the interview. Thereafter, a set of questions about practical help and conflict among listed family members was asked. Practical help included offering services such as help with childcare, shopping, chores, or transportation. We measured practical help using the following question: "Who would give practical help to $\mathrm{X}$ (that is, to the respondent and then to each individual included in the respondent's family network, considered one by one) during routine or minor troubles?" Family conflict was investigated with the following question: "Each family has its conflicts and tensions. In your opinion, who makes $\mathrm{X}$ (that is, to the respondent and then to each individual included in the respondent's family network, considered one by one) angry?" For each of these questions, respondents could select one or more significant family members by their name or none of them if they considered that no one was concerned by these questions within their family network. Respondents had to evaluate not only their family relationships but also those among all of their significant family members [Widmer et al. (2013)].

We considered four structural indexes for practical help and conflict within family networks. First, we computed density indexes to assess practical help and conflict among family members. This indicator refers to the extent to which all family 
members included were interconnected through practical help or conflict. The high density of practical help indicates tight practical help exchanges, and the high density of conflict reveals highly tense ties within the family network. It was estimated by the number of supportive or conflicting ties divided by the number of available pairs of family members, including respondents [Hanneman and Riddle (2005)]. Density indexes varied from 0 to 1 (when all included family members are interconnected through supportive/conflicting ties).

Furthermore, to assess respondents' centrality within family networks, we calculated respondents' betweenness centrality, which indicated the extent to which respondents were intermediaries between their significant family members who were otherwise not connected. This was computed as the ratio of all the shortest paths between any two significant family members who went through the respondents [Hanneman and Riddle (2005)]. Respondents were considered central in practical help exchanges or in family tensions if they were lying between all, or almost all, of their family members' help or tense ties. These indexes varied from 0 to 1 (when all of the family members go through respondents to reach each other in practical help/in conflict).

Finally, to capture respondents' roles (giver and recipient, respectively) in support exchanges and conflict within their family configurations, we computed respondents' in- and out-degrees. Respondents' in-degree indicated the number of family members helped/upset by respondents. It reflected the importance of respondents as help providers or as tension activators within their family network. These indexes ranged from 0 to 1 , with 1 indicating that all significant family members were helped/ upset by the respondent. Likewise, respondents' out-degree concerned the number of family members who provided respondents with practical help or who upset respondents. They ranged from 0 to 1 (when all significant family members helped the respondent/upset the respondent). All these indexes controlled for the family networks size. Network properties are graphically illustrated in Figure 1, which shows two sampled family networks characterized by different patterns of practical help exchanges among family members, with the arrows pointing to support providers.

The first family network (a) showed a high score on density (1.0), as all the family members were interconnected through practical help. However, ego's betweenness centrality was low $(0.0)$, revealing that the respondent did not hold a central position within his/her family network. In regards to roles within the family, the respondent was active in providing practical help to family members (in-degree: 1.0), and in receiving support from all of them (out-degree: 1.0). In contrast, the second family network (b) featured a lower score on density (0.4) and a higher score on ego's betweenness centrality (1.0). The respondent was indeed in the center of family exchanges, playing the role of an intermediary between his/her family members and was equally very active in both providing (in-degree: 1.0) and receiving practical help (out-degree: 1.0) within his/her family network.

We considered cantons, which are major regional entities of Switzerland, age, being married, having offspring, and education as control variables. Cantons were coded as a fifth-level variable $(1=$ Geneva, $2=$ Valais, $3=$ Bern, $4=$ Basel, $5=$ Ticino $)$. We distinguished six age groups: respondents aged (1) 65-69 years, (2) 70-74 years, (3) 75-79 years, (4) 80-84 years, (5) 85-89 years, and (6) 90 years and over. Then, we controlled for the impact of being married $(0=$ unmarried, $1=$ married $)$, having offspring $(0=$ no child, $1=$ having at least one living child, $2=$ having at least one living grandchild) on giving economic support within the family. Furthermore, education was included ( $1=$ low [compulsory school], $2=$ medium [vocational training 


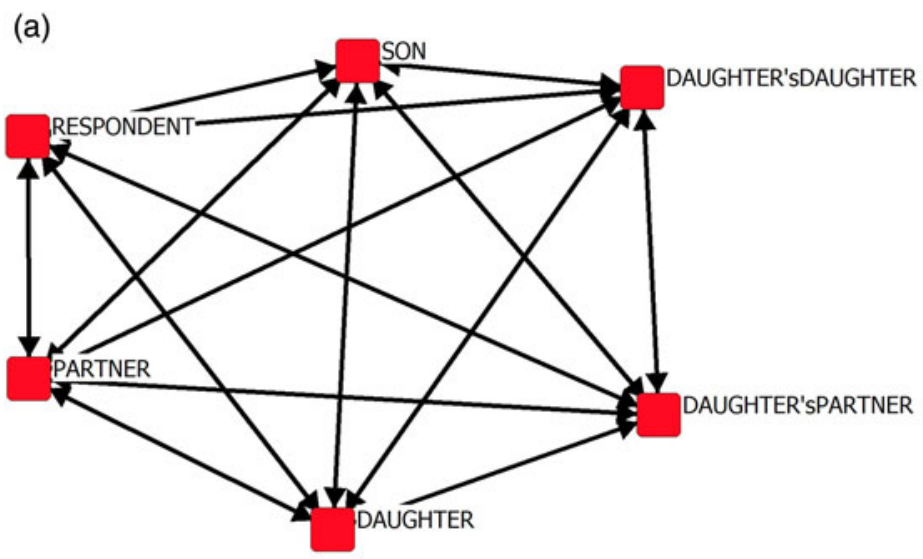

(b)

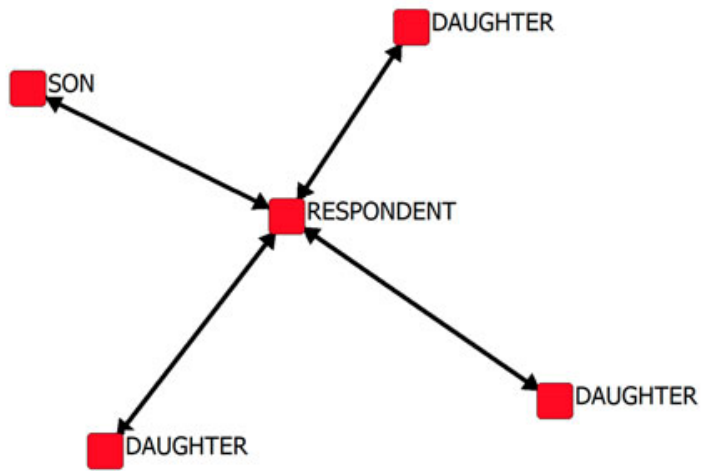

Fig. 1. Sampled family networks.

and upper secondary], 3 = high [higher technical or vocational school or university]), as the literature shows that the level of education is a very good proxy of the socioeconomic position of the elderly [Gabriel et al. (2015)], which is significantly related to providing economic help. Table 1 shows the characteristics of the surveyed population on the main variables presented above.

\subsection{Data analysis}

In each set of analyses, we considered primarily the "giving economic help at least rarely" indicator as the dependent variable, and tested, secondarily, the "giving economic help at least sometimes" indicator. For the sake of parsimony, with all results pointing in the same direction, the details of the second set of analyses are not shown in this paper. ${ }^{1}$ We first conducted a set of descriptive analyses to compare indexes of network properties according to whether or not one provides financial support to a family member. Next, we computed adjusted Wald test statistics to test

\footnotetext{
${ }^{1}$ Tables can be requested from the corresponding author.
} 
Table 1. Surveyed population characteristics on key variables

\begin{tabular}{|c|c|c|c|c|c|c|c|}
\hline & \multicolumn{2}{|c|}{ Total } & \multicolumn{2}{|c|}{ Women } & \multicolumn{2}{|c|}{ Men } & $\begin{array}{l}\chi^{2}-p \\
\text { value }\end{array}$ \\
\hline \multicolumn{8}{|l|}{ Independent variable } \\
\hline \multicolumn{8}{|c|}{ Giving financial support to family members } \\
\hline Never & \multicolumn{2}{|c|}{$66 \%$} & \multicolumn{2}{|c|}{$70 \%$} & \multicolumn{2}{|c|}{$59 \%$} & \\
\hline Rarely & \multicolumn{2}{|c|}{$13 \%$} & \multicolumn{2}{|c|}{$12 \%$} & \multicolumn{2}{|c|}{$14 \%$} & 0.00 \\
\hline Sometimes & \multicolumn{2}{|c|}{$17 \%$} & \multicolumn{2}{|c|}{$14 \%$} & \multicolumn{2}{|c|}{$20 \%$} & \\
\hline Often & \multicolumn{2}{|c|}{$5 \%$} & \multicolumn{2}{|c|}{$4 \%$} & \multicolumn{2}{|c|}{$6 \%$} & \\
\hline $\begin{array}{l}\text { Practical help network } \\
\text { properties }\end{array}$ & M & $S D$ & M & $S D$ & M & $S D$ & \\
\hline Density & 0.42 & 0.29 & 0.40 & 0.29 & 0.44 & 0.30 & 0.00 \\
\hline Centrality & 0.13 & 0.22 & 0.13 & 0.21 & 0.13 & 0.22 & 0.70 \\
\hline In-degree & 0.63 & 0.38 & 0.59 & 0.39 & 0.69 & 0.36 & 0.00 \\
\hline Out-degree & 0.44 & 0.36 & 0.43 & 0.35 & 0.45 & 0.36 & 0.20 \\
\hline $\begin{array}{l}\text { Conflict structural } \\
\text { network properties }\end{array}$ & M & $S D$ & M & $S D$ & M & $S D$ & \\
\hline Density & 0.12 & 0.19 & 0.12 & 0.18 & 0.13 & 0.19 & 0.09 \\
\hline Centrality & 0.02 & 0.09 & 0.02 & 0.08 & 0.03 & 0.10 & 0.05 \\
\hline In-degree & 0.15 & 0.25 & 0.13 & 0.24 & 0.18 & 0.27 & 0.00 \\
\hline Out-degree & 0.15 & 0.24 & 0.15 & 0.23 & 0.15 & 0.25 & 0.78 \\
\hline \multicolumn{8}{|l|}{ Control variables } \\
\hline \multicolumn{8}{|l|}{ Level of education } \\
\hline $\begin{array}{l}\text { Low } \\
\text { (compulsory school) }\end{array}$ & \multicolumn{2}{|c|}{$18 \%$} & \multicolumn{2}{|c|}{$25 \%$} & \multicolumn{2}{|c|}{$10 \%$} & \\
\hline $\begin{array}{l}\text { Medium } \\
\text { (vocational training } \\
\text { and upper secondary) }\end{array}$ & \multicolumn{2}{|c|}{$53 \%$} & \multicolumn{2}{|c|}{$54 \%$} & \multicolumn{2}{|c|}{$53 \%$} & 0.00 \\
\hline $\begin{array}{l}\text { High } \\
\text { (higher technical or } \\
\text { vocational school or } \\
\text { university) }\end{array}$ & \multicolumn{2}{|c|}{$29 \%$} & \multicolumn{2}{|c|}{$22 \%$} & \multicolumn{2}{|c|}{$38 \%$} & \\
\hline Married & \multicolumn{2}{|c|}{$60 \%$} & \multicolumn{2}{|c|}{$47 \%$} & \multicolumn{2}{|c|}{$76 \%$} & 0.00 \\
\hline \multicolumn{8}{|l|}{ Offspring } \\
\hline No child & & & & & & & \\
\hline At least one living child & & & & & & & 0.00 \\
\hline $\begin{array}{l}\text { At least one living } \\
\text { grandchild }\end{array}$ & & & & & & & \\
\hline
\end{tabular}

Note: Weighted analyses; $n=2,991$. 
the null hypothesis that the means are equal and thus assess the statistical significance of each network property separately. Separate analyses were run for women and men to examine gender differences in network properties and how they were related to giving economic support in the family.

Then, we conducted a two-step logistic regression analyses to adjust statistical estimates for different covariates. First, considering that the various networks properties were interdependent, we integrated different indexes of network properties to examine the ones that were most related to the propensity to provide financial support within the family (Step 1). Second, we added a set of control variables (Step 2). Thereafter, we ran two different sets of models according to the different network indexes selected. Model A considered densities and respondents' betweenness centralities within practical help and conflict networks. Model B included densities and respondents' in- and out-degrees within practical help and conflict networks. Results of these regression analyses were expressed in terms of probabilities of financially supporting family members by varying levels of network property values and were plotted into graphics to specify the magnitude of the observed associations.

In addition to regression analyses, we calculated Pearson's correlations between all the indexes of network properties within practical help and conflict networks to examine the extent to which they were all interrelated. These results support our understanding of network properties' effect when included together in the regression models. We ran all of these analyses in Stata and used weighting coefficients that have been computed to restore the real population structure since the survey sample was stratified [StataCorp. (2011)].

\section{Results}

The first set of descriptive analyses compares the means of the various indexes of network properties between the older parents that gave financial support $(30 \%$ of older women and $41 \%$ of older men) and those that did not (Table 2). Results show significant differences (i.e., $p$ value of Wald test $<0.5$ ) between givers and non-givers, some of them varying according to gender.

Overall, among older men and women, two network properties were positively linked to giving financial support to family members. The first one was the number of family members practically helped by the respondents within their family network (i.e., respondents' in-degree within practical help exchanges). This index informs whether older adults were important providers of practical help within the family. Respondents-women as well as men-who gave financial support to some selected family members, helped a higher number of family members with different services than those who did not give any financial support. The second network property is the density of conflicting ties that is higher within the family networks of older adults who gave financial support. In addition, the density of practical help was significantly higher when respondents gave financial support than when they did not give any, although only among older men. Among older women, centrality within practical help exchanges was positively linked to giving financial support to family members.

Tables 3 and 4 include the logistic regressions that estimate the associations of these various network properties on providing financial support. Results on the propensity to give financial support confirm, on the one hand, the significant and positive association between high density of practical help and giving financial support among older men 
Table 2. Network properties of giving financial support and gender

\begin{tabular}{|c|c|c|c|c|c|c|c|c|c|c|}
\hline & \multicolumn{5}{|c|}{ Women } & \multicolumn{5}{|c|}{ Men } \\
\hline & \multicolumn{2}{|c|}{$\begin{array}{l}\text { Gives economic } \\
\text { support }\end{array}$} & \multicolumn{2}{|c|}{$\begin{array}{l}\text { Does not give } \\
\text { financial support }\end{array}$} & \multirow[b]{2}{*}{ Wald test } & \multicolumn{2}{|c|}{$\begin{array}{c}\text { Gives economic } \\
\text { support }\end{array}$} & \multicolumn{2}{|c|}{$\begin{array}{l}\text { Does not give } \\
\text { financial support }\end{array}$} & \multirow[b]{2}{*}{ Wald test } \\
\hline & M & SD & M & SD & & M & SD & M & SD & \\
\hline \multicolumn{11}{|l|}{ Practical help } \\
\hline Density & 0.42 & 0.26 & 0.39 & 0.30 & 0.14 & 0.47 & 0.27 & 0.43 & 0.31 & 0.01 \\
\hline Centrality & 0.17 & 0.23 & 0.12 & 0.21 & 0.00 & 0.15 & 0.22 & 0.12 & 0.22 & 0.06 \\
\hline In-degree & 0.70 & 0.33 & 0.54 & 0.40 & 0.00 & 0.77 & 0.31 & 0.63 & 0.39 & 0.00 \\
\hline Out-degree & 0.43 & 0.33 & 0.43 & 0.36 & 0.90 & 0.47 & 0.34 & 0.44 & 0.37 & 0.22 \\
\hline \multicolumn{11}{|l|}{ Conflict } \\
\hline Density & 0.13 & 0.18 & 0.11 & 0.19 & 0.04 & 0.15 & 0.20 & 0.12 & 0.19 & 0.03 \\
\hline Centrality & 0.02 & 0.08 & 0.02 & 0.08 & 0.38 & 0.03 & 0.11 & 0.02 & 0.08 & 0.13 \\
\hline In-degree & 0.16 & 0.24 & 0.13 & 0.24 & 0.05 & 0.19 & 0.27 & 0.17 & 0.27 & 0.11 \\
\hline Out-degree & 0.16 & 0.22 & 0.14 & 0.24 & 0.17 & 0.17 & 0.24 & 0.14 & 0.25 & 0.10 \\
\hline
\end{tabular}

Note: Weighted analyses; adjusted Wald test; $n=2,991$. 
Table 3. Logistic regressions on giving financial support with density and ego's centrality

\begin{tabular}{|c|c|c|c|c|c|c|c|c|}
\hline & \multicolumn{4}{|c|}{ Women } & \multicolumn{4}{|c|}{ Men } \\
\hline \multicolumn{9}{|l|}{ Practical help } \\
\hline Density & 1.15 & 0.51 & 1.29 & 0.28 & 1.52 & 0.03 & 1.56 & 0.04 \\
\hline \multicolumn{9}{|l|}{ Conflict } \\
\hline Density & 1.83 & 0.08 & 1.82 & 0.10 & 1.51 & 0.21 & 1.25 & 0.51 \\
\hline Centrality & 1.05 & 0.95 & 0.96 & 0.96 & 1.81 & 0.37 & 1.18 & 0.80 \\
\hline \multicolumn{9}{|c|}{ Regions (ref. Geneva) } \\
\hline Valais & & & 0.66 & 0.05 & & & 0.67 & 0.05 \\
\hline \multicolumn{9}{|l|}{ Age (ref. 65-69) } \\
\hline $70-74$ & & & 1.25 & 0.24 & & & 1.08 & 0.65 \\
\hline $75-79$ & & & 0.98 & 0.90 & & & 1.18 & 0.35 \\
\hline $80-84$ & & & 0.81 & 0.33 & & & 0.72 & 0.08 \\
\hline $85-89$ & & & 0.57 & 0.02 & & & 0.51 & 0.00 \\
\hline 90 and older & & & 0.66 & 0.12 & & & 0.37 & 0.00 \\
\hline
\end{tabular}




\begin{tabular}{|c|c|c|c|c|}
\hline $\begin{array}{l}\text { Married (ref. } \\
\text { unmarried) }\end{array}$ & 1.11 & 0.47 & 1.30 & 0.08 \\
\hline $\begin{array}{l}\text { At least one } \\
\text { living child }\end{array}$ & 1.30 & 0.32 & 2.24 & 0.00 \\
\hline $\begin{array}{l}\text { At least one } \\
\text { living } \\
\text { grandchild }\end{array}$ & 1.99 & 0.00 & 2.98 & 0.00 \\
\hline \multicolumn{5}{|c|}{$\begin{array}{l}\text { Level of education } \\
\text { (ref. medium) }\end{array}$} \\
\hline Low & 0.59 & 0.00 & 0.99 & 0.97 \\
\hline High & 1.18 & 0.29 & 1.71 & 0.00 \\
\hline
\end{tabular}

Note: Weighted analyses; $n=2,991$. 
Table 4. Logistic regressions on giving financial support with density and ego's in-degrees and out-degrees

\begin{tabular}{|c|c|c|c|c|c|c|c|c|}
\hline & \multicolumn{4}{|c|}{ Women } & \multicolumn{4}{|c|}{ Men } \\
\hline & \multicolumn{2}{|c|}{ Model B1 } & \multicolumn{2}{|c|}{ Model B2 } & \multicolumn{2}{|c|}{ Model B1 } & \multicolumn{2}{|c|}{ Model B2 } \\
\hline & OR & $p>z$ & OR & $p>z$ & OR & $p>z$ & OR & $p>z$ \\
\hline \multicolumn{9}{|l|}{ Practical help } \\
\hline Density & 0.20 & 0.00 & 0.26 & 0.01 & 0.35 & 0.01 & 0.45 & 0.06 \\
\hline In-degree & 6.02 & 0.00 & 4.93 & 0.00 & 4.98 & 0.00 & 3.84 & 0.00 \\
\hline Out-degree & 1.26 & 0.42 & 1.26 & 0.44 & 1.22 & 0.47 & 1.19 & 0.54 \\
\hline \multicolumn{9}{|l|}{ Conflict } \\
\hline Density & 3.84 & 0.11 & 4.64 & 0.08 & 2.86 & 0.15 & 2.65 & 0.18 \\
\hline In-degree & 0.69 & 0.43 & 0.62 & 0.33 & 0.70 & 0.37 & 0.68 & 0.32 \\
\hline Out-degree & 0.64 & 0.34 & 0.62 & 0.33 & 0.80 & 0.58 & 0.72 & 0.44 \\
\hline \multicolumn{9}{|c|}{ Canton (ref. Geneva) } \\
\hline Valais & & & 0.73 & 0.14 & & & 0.63 & 0.02 \\
\hline Bern & & & 0.67 & 0.05 & & & 0.86 & 0.45 \\
\hline Basel & & & 0.85 & 0.41 & & & 0.60 & 0.01 \\
\hline Ticino & & & 0.83 & 0.40 & & & 0.77 & 0.21 \\
\hline \multicolumn{9}{|c|}{ Age (ref. 65-69) } \\
\hline $70-74$ & & & 1.30 & 0.17 & & & 1.10 & 0.60 \\
\hline $75-79$ & & & 1.10 & 0.65 & & & 1.24 & 0.24 \\
\hline $80-84$ & & & 0.98 & 0.94 & & & 0.77 & 0.17 \\
\hline $85-89$ & & & 0.69 & 0.13 & & & 0.59 & 0.01 \\
\hline
\end{tabular}




\begin{tabular}{|c|c|c|c|c|}
\hline 90 and older & 0.94 & 0.83 & 0.46 & 0.00 \\
\hline $\begin{array}{l}\text { Married (ref. } \\
\text { unmarried) }\end{array}$ & 1.07 & 0.63 & 1.25 & 0.16 \\
\hline \multicolumn{5}{|c|}{ Offspring (ref. without) } \\
\hline $\begin{array}{l}\text { At least one } \\
\text { living child }\end{array}$ & 1.22 & 0.45 & 2.13 & 0.01 \\
\hline $\begin{array}{l}\text { At least one } \\
\text { living } \\
\text { grandchild }\end{array}$ & 1.87 & 0.00 & 2.75 & 0.00 \\
\hline \multicolumn{5}{|c|}{$\begin{array}{l}\text { Level of education } \\
\text { (ref. medium) }\end{array}$} \\
\hline Low & 0.60 & 0.00 & 1.05 & 0.83 \\
\hline High & 1.21 & 0.23 & 1.65 & 0.00 \\
\hline
\end{tabular}

Note: Weighted analyses; $n=2,991$. 


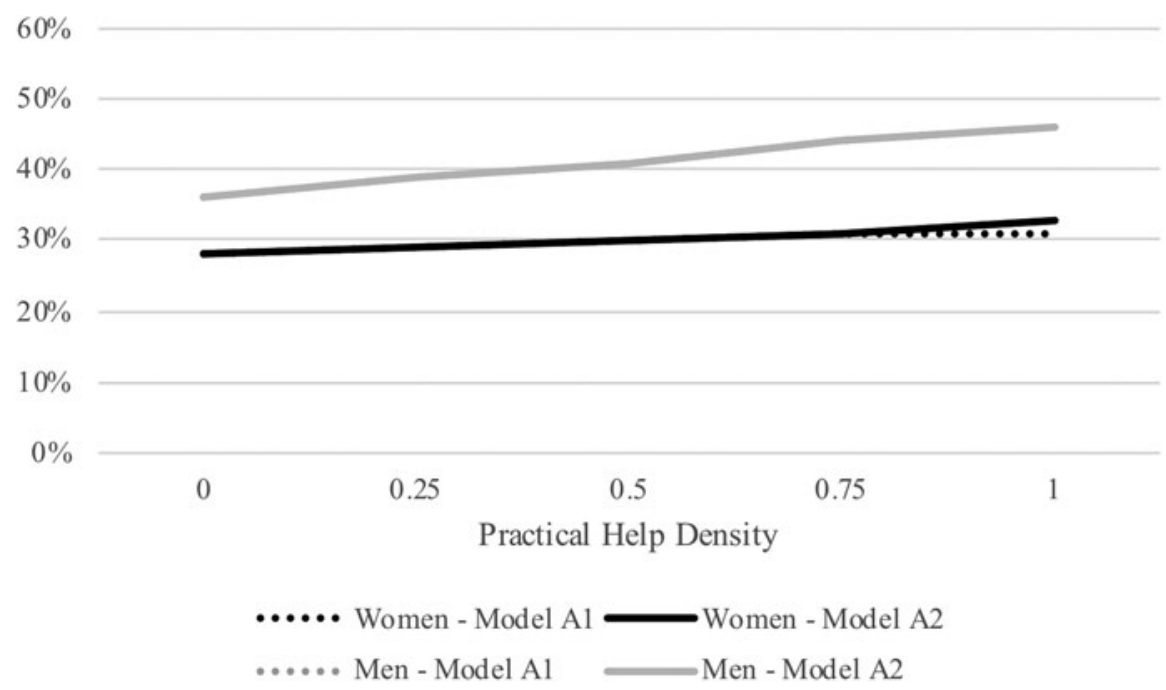

Fig. 2. Probability (in \%) to give financial support according to network density of practical help (Model A).

(Table 3). On average, the probability to financially support family members among men who had a high density of practical help within their network ( $=1$ ) was $46 \%$ : it was $36 \%$ among those who had a low density of practical help (=0) (Figure 2).

Results similarly confirm the significant and positive relation between respondents' centrality within practical help exchanges and the propensity of giving financial support among older women. On average, the probability to financially support family members among women who had high centrality in practical help within their network (=1) was 47\%: it was only $27 \%$ among those who had low centrality in practical help (0) (Figure 3). All results presented here were obtained after controlling for sociodemographic variables. Overall, the results remained stable between models 1 and 2 as shown in Figures 2 and 3 (the curves overlapped each other or differed only slightly).

The second set of regression models (Table 4) includes densities of both practical help and conflict in combination with the number of family members helped by the respondent (ego's in-degree in help exchanges) and helping the respondent (ego's out-degree in help exchanges) and with the number of family members upset by the respondent (ego's in-degree in conflict) and upsetting the respondent (ego's out-degree in conflict). Results show that older men and women that significantly helped a high number of family members with different types of services were more likely to give financial support. Older women and men who had high in-degree in practical help $(=1)$ had an average probability to give financial help of $43 \%$ and $50 \%$, respectively. Conversely, those who had low in-degree in practical help $(=0)$ had a probability to give money of $14 \%$ and $22 \%$, respectively (Figure 4). These findings confirm the strong association-among men as well as women-between being an active provider of different types of services within the family network and giving financial support to family members. However, being helped by a high number of family members is not significantly related to the propensity to provide financial help, regardless of the respondent's gender. 


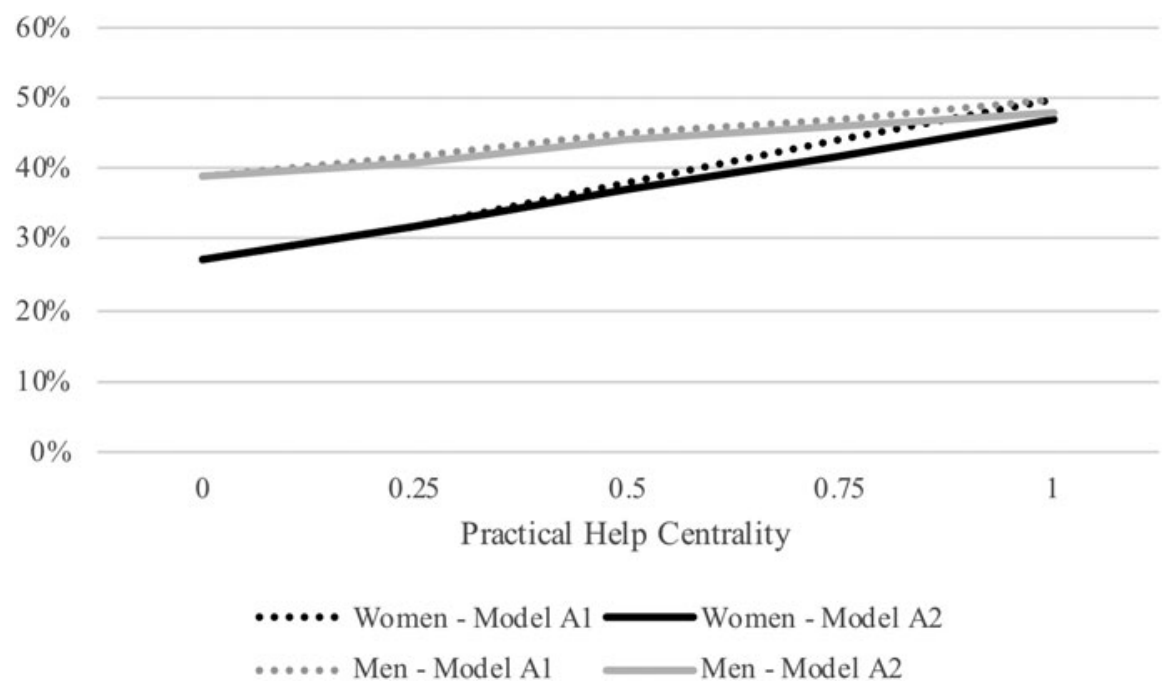

Fig. 3. Probability (in \%) to give financial support according to network centrality of practical help (Model A).

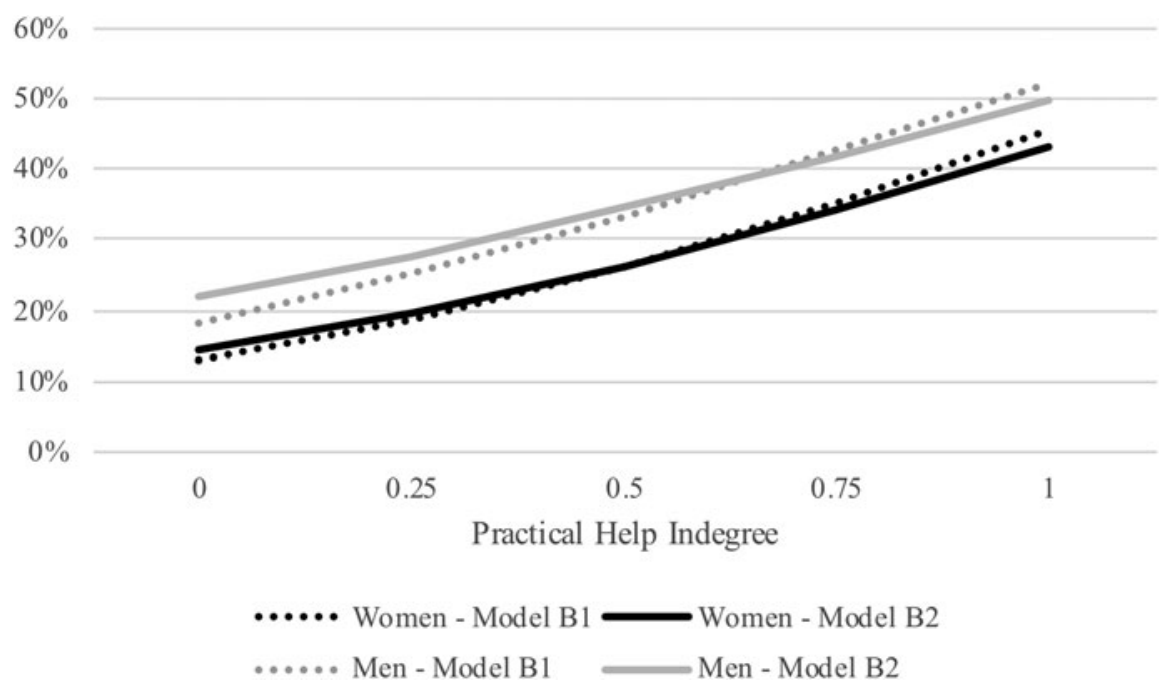

Fig. 4. Probability (in \%) to give financial support according to practical help in-degree (Model B).

Moreover, with the inclusion of indexes measuring ego's roles (i.e., in- and out-degrees in practical help exchanges) in the analysis, the density of practical help becomes negatively linked to the likelihood of giving economic support. This result might be explained by the strong and positive correlation between the density of practical help and the number of family members helped by respondents (i.e., respondents' in-degree in practical help; Table 5). Thus, the high number of family members helped by older parents-men or women-contributes greatly to the higher density of practical support within their 
Table 5. Correlations between network properties for practical help and conflict by gender

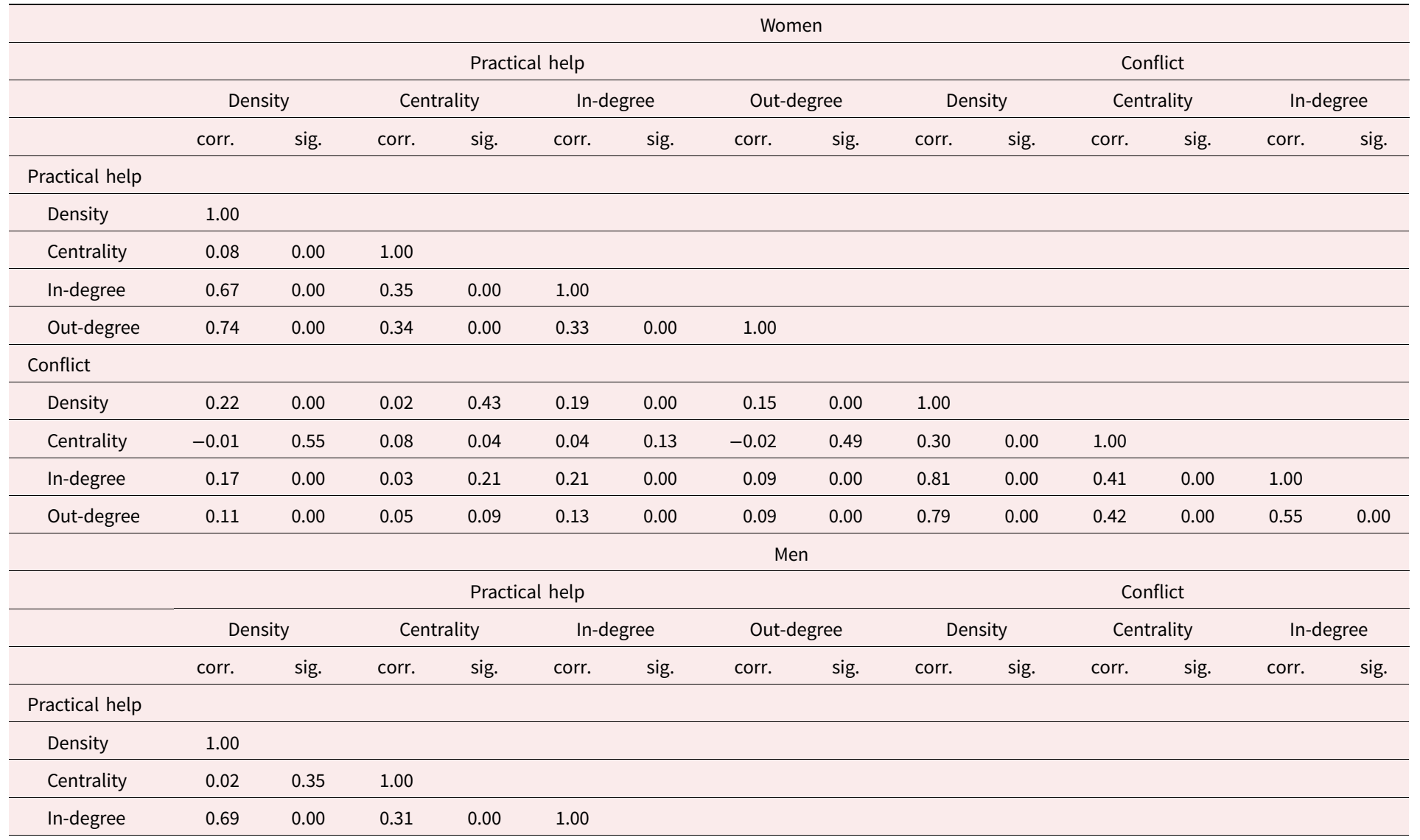




\begin{tabular}{|c|c|c|c|c|c|c|c|c|c|c|c|c|c|c|}
\hline Out-degree & 0.77 & 0.00 & 0.31 & 0.00 & 0.40 & 0.00 & 1.00 & & & & & & & \\
\hline \multicolumn{15}{|l|}{ Conflict } \\
\hline Density & 0.20 & 0.00 & 0.02 & 0.39 & 0.20 & 0.00 & 0.09 & 0.00 & 1.00 & & & & & \\
\hline Centrality & 0.04 & 0.10 & 0.09 & 0.03 & 0.09 & 0.00 & 0.03 & 0.20 & 0.33 & 0.00 & 1.00 & & & \\
\hline In-degree & 0.15 & 0.00 & 0.04 & 0.14 & 0.20 & 0.00 & 0.07 & 0.02 & 0.80 & 0.00 & 0.49 & 0.00 & 1.00 & \\
\hline Out-degree & 0.10 & 0.00 & 0.04 & 0.19 & 0.14 & 0.00 & 0.05 & 0.08 & 0.80 & 0.00 & 0.41 & 0.00 & 0.56 & 0.00 \\
\hline
\end{tabular}

Note: Weighted analyses; $n=2,991$. 
family networks. Consequently, the inclusion of this measure in the analyses eliminatesand even reverses - the positive relation between the density of practical help and giving of financial support observed in the comparison of means (Table 2).

Regression analyses results underline that respondents' centrality in practical help (especially for women), their active role as providers of practical help within their family networks, and the related density of practical help within family networks (only for men) stimulate their propensity of giving money to family members. These results withstand in models including sociodemographic variables. Regarding control variables, results overall correspond to findings in other studies. They show negative relations between the propensity to provide financial support and increasing age, the absence of offspring and lower socioeconomic status. These observed effects varied to some extent according to older adult's gender: age and the absence of offspring had a broader negative impact on men's financial support than on women's propensity to give money. Moreover, this propensity was associated with a higher level of education for men (higher technical/vocational school or university) than for women (vocational training and upper secondary).

\section{Discussion}

The purpose of this study was to grasp inter vivos financial transfers from older parents to family members within the broader and complex network of positive and negative family ties. We extended prior research by exploring financial support issues beyond the "provider and receiver" dyad and by investigating its embeddedness within the meso level of family networks [Widmer $(1999,2006,2016)]$. Based on the social network literature, we made four hypotheses about the association of giving financial support to family members with different family network properties. Both support and conflict alongside gender differences were considered in this set of hypotheses.

The first hypothesis, which stated that giving financial support was linked to a higher density of practical support only among men, was confirmed. Highly dense exchanges of practical help within family configurations encourage older men to support their family members financially. In turn, older men's financial support could foster the mobilization of supportive ties within family configurations. Although men are usually less active and less invested in family ties than women are, they can often rely on their partners-because men are more likely to be partnered in old age than women are-to mobilize support exchanges among the other family members who form their family configurations [Cornwell (2011); Girardin and Widmer (2015)].

This finding stresses that men's propensity to provide financial support is related to the dynamics of supportive ties within their family networks. It reveals men's stronger dependence on their family networks, which influences their financial investment in it, and the impact of dense family networks on men's support behavior. As most family members are connected, dense family networks are associated not only with collective support but also with control and normative pressure-in terms of support obligations - which leads to family solidarity [Coleman (1988); Widmer (1999, 2006, 2016)]. Having played the family "breadwinner" role throughout their life, men are usually expected by other family members to provide economic support within their family network, regardless of their age. In other words, men, embedded within dense family ties, are compelled to fulfill their family role of economic provider, even in old age.

Furthermore, the results confirmed the second hypothesis, which postulated the link between women's high centrality within practical help exchanges and their propensity 
to give financial support. Given their family role as kin keepers, women are particularly active in providing support of all kinds to various family members in need. This greater involvement in family ties contributes to their central positions within their family configurations [Cornwell (2011); Girardin and Widmer (2015)]. In turn, keeping a central position within family ties demands energy, time, and resources [Cornwell (2009a, 2009b)]. Because money is related to social power [Bourdieu (1986)] and men's dominant role as "breadwinners" in the studied birth cohorts [Oris et al. (2017)], it may enable older women who provide money to their family members to consolidate their influential position within their family configuration. As a crucial economic resource, money provides older women with a pivotal position in exchanges that is associated with greater relational power within their family networks [Widmer (2016)]. Being central, they may control the distribution of resources between the other family members by playing the role of an intermediary within their family configurations [Wasserman and Faust (1994)]. The meaning of money may reinforce this relational power [Zelizer (2017)].

Concerning the negative ties, the third hypothesis, which stated that the propensity to provide financial support was positively related to conflict density, particularly among women, was not validated. The descriptive analyses show that conflict density was linked to financial support not only among the older women but also among the older men as well (Table 2). This result, however, was not confirmed by regression analysis, which included network properties related with practical help (Tables 3 and 4). Because conflict density positively correlates with practical help density and with the number of family members helped by respondents (in-degree), which are both associated with financial support (Table 5), the relation between conflict density and providing financial support disappears. This finding suggests that tensions are not particularly associated with financial transfers, but rather with the overall support exchanges with which they correlate. Put differently, it is not money itself-as an important source of power within family networks-that is associated with conflict; rather, the crucial resource it represents and its inclusion in the overall pattern of support exchanges is the source of tensions and ambivalence because of the interdependencies it generates within families [Lüscher and Pillemer (1998); Widmer (2016); Girardin et al. (2018)]. Furthermore, the last hypothesis (4), which postulated a positive link between the egos' centrality in conflict and the propensity to provide financial support, especially among women, was not confirmed. Like men, women who provide financial support are not more central in conflict networks than those who do not.

Our analyses also revealed that the active role of providing practical help within one's family network is strongly associated with the propensity of giving money to family members. Not only women but also men showed positive links between the number of family members they help with various services and the propensity to give money. Indeed, the propensity to support a family member financially increased with the number of family members helped with other types of support, regardless of the respondent's gender. Thus, financial support is part of a larger set of other practical helping acts older parents provide, which gives meaning to and supports financial transfers. In other words, a financial transfer does not happen in isolation from a set of other types of supportive acts, nor does it compensate for a lack of other practical support. This finding highlights the important role of older adults as support providers within their family network and, once again, the embeddedness of financial transfer in this general pattern. 
Finally, we observed that men who provided financial support did not receive practical help from a higher number of family members than those who did not. In the case of financial transfers within families, expectations of receiving any support back from their family members, as a counterpart to their investment did not influence men or women's propensity to give money to one or another relative. In particular, this finding contradicts previous research showing gendered differences in motives for providing financial support, with women leaning more toward unconditional giving, whereas men expect more reciprocity [Kohli and Künemund (2003)]. In our data, men, like women, do not seem to provide financial support in a balance of a greater amount of practical support received from their family members.

While previous research on financial inter vivos transfers from older parents to their family members focused on the giver-receiver dyad, our study highlights the relational dimensions of the financial support provided within families by older adults and underlines the relevance of considering the larger context of family configuration in which both the giver and the receiver are embedded. Indeed, the propensity to financially support family members is not only a question of wealth or need, but it also depends on the dynamics of family ties, the roles older parents play in family exchanges and the position they occupy in their family networks.

\subsection{Limitations}

This study has some limitations. First, the name generator of family members was limited to five to keep the interview time manageable within the frame of a multifaceted survey such as VLV. It is quite likely that the inclusion of a greater number of network members would have revealed an even larger diversity of family networks in old age by allowing respondents to include weaker family ties. Literature has underlined that size and the composition of family networks have an impact on family networks properties; smaller size and homogeneous composition being usually associated with denser family ties and a lower centrality of respondent [Widmer (2006, 2016)]. However, previous studies have shown that, even with this rather restrictive name generator, many individuals in old age cite various family members, leading to different network properties [Girardin and Widmer (2015)]. Moreover, this 5-limit has some advantages. It limited the study to core family members, as most salient alters, whoever they are, are cited first in free listing tasks [d'Andrade (1995)]. These might be the ones to whom older adults are more prone to provide financial support. Subsequently, the 5-name generator allowed us to reduce respondents burden in completing the VLV survey, more so with respondents aged 65 and above. Increasing the number could have jeopardized the data quality provided by respondents [Merluzzi and Burt (2013)].

Second, we have no information on which specific family members (non-cohabitant) the financial support recipients are. Therefore, we cannot verify if money is given to some family members and not to others, as stated in the literature. Similarly, we cannot examine whether the provided financial support is part of a reciprocal exchange within specific dyads as information on recipients' identity is missing. Nevertheless, the indexes of network properties allow capturing how the older adults' propensity to provide financial support is related to the density of supportive ties within their family network and their role and position within it.

Third, the VLV question on providing financial support was unprecise not only on the identity of recipients but also on the time frame of the given support. In addition, 
the frequency expressions used in the frequency scale of financial support were vague, tended to overlap and might be interpreted in different ways [Bocklisch et al. (2012)]. A further challenge will be to find the proper way of questioning the respondents about the amount of money exchanged in financial support, an important piece of information that is missing in VLV data. Further research focusing on financial transfers within the family in old age could collect such data; however, it will be delicate and could result in a lot of missing information.

Fourth, the FNM questionnaire was ego-centered, and social desirability may have influenced respondents' perception of their role and position within their family networks. Respondents may have overestimated their role in exchanges, compared with those of their cited family members. Similarly, they may have understated tensions, as respondents are usually reluctant to report family conflict. Finally, we used the first wave of the VLV survey, which includes two waves, in order to keep a larger and more representative sample of the Swiss older adults population. Therefore, we could not determine with certainty whether family network dynamics are the cause of providing financial support, or whether this type of support is the source of family networks dynamics. A longitudinal verification is now possible using the second wave of the VLV study. It would enable us to some extent estimate the causal ordering of such variables.

Despite these caveats, exploring financial transfers from older adults to their family members using a configurational approach allowed us to transcend the dyadic level, and thus, consider the complex network of positive and negative interdependencies in which dyads are embedded, and its inexorable influence on them.

\subsection{Final words: the social stratification of family support}

We now conclude by stressing the societal implications of our results. As highlighted in the literature [Kohli and Albertini (2008); Le Goff et al. (2017)], older parents' financial support is crucial for children or grandchildren who need help to face various life transitions or disruptive events across the course of their lives. However, our results show that older parents' financial support is also beneficial to family dynamics. Similar to all of the other types of practical help offered by older parents, financial support is an important resource that contributes to maintaining practical help exchanges within family networks and reaffirms older adults' active roles as providers in family exchanges, even in later life. Moreover, giving money enables older women to sustain and reinforce their central position within their family networks.

However, this type of support is socially stratified; those with financial resources, who are notably those with higher education [Oris et al. (2017)], have a higher propensity to provide financial support to their family members [Kohli (1999); Kohli and Künemund (2003); Albertini et al. (2007); Albertini and Radl (2012)]. This means those older adults who have poor economic resources, and for whom providing financial support is difficult, have a higher risk of losing their role of providers and their position within their family configurations. In addition, they have limited access to practical help exchanges within their family networks (financial support and practical help exchanges being closely related). Moreover, limited economic resources may exacerbate tensions within family networks, placing older parents in a difficult situation [Girardin et al. (2018)]. Overall, wealthy older adults are better able to give financial support and other types of practical support to their family members than those who have only limited socioeconomic resources, stressing 
the unequal dimension of financial transfers. Thus, if inter vivos financial transfers from older parents to selected family members are to be described as leveling social inequalities within families [Kohli and Künemund (2003); Kohli (2004); Künemund et al. (2005)], it should be stated that contrarily, they deepen social inequalities between families from various social backgrounds.

Acknowledgements. The authors are grateful to the Swiss National Science Foundation for their financial assistance and two anonymous reviewers for their careful reading and valuable inputs in this paper.

Financial support. This work was supported by a Sinergia project (grant number CRSII1_129922/1) and the Swiss National Centre of Competence in Research LIVES-Overcoming Vulnerability: Life Course Perspectives (NCCR LIVES; grant number 51NF40-160590), both financed by the Swiss National Science Foundation.

\section{References}

Albertini, Marco, Martin Kohli and Claudia Vogel (2007) Intergenerational transfers of time and money in European families: common patterns-different regimes? Journal of European Social Policy 17(4), 319-334.

Albertini, Marco and Jonas Radl (2012) Intergenerational transfers and social class: inter-vivos transfers as means of status reproduction? Acta Sociologica 55(2), 107-123.

Antonucci, Toni C. (2001) Social relations: an examination of social networks, social support, and sense of control. In James E. Birren and K. Warner Schaie (eds.), Handbook of the Psychology of Aging, pp. 427-453. San Diego, CA: Academic Press.

Antonucci, Toni C. and James S. Jackson (1990) The role of reciprocity in social support. In Barbara R. Sarason and Gregory R. Pierce (eds.), Social Support: An Interactional View, pp. 173-198. Oxford, UK: John Wiley and Sons.

Armi Cholley, Franca, Edith Guilley and Christian Lalive d'Epinay (2008) Health: support provided and received in advanced old age. Zeitschrift für Gerontologie und Geriatrie 41, 56-62.

Attias-Donfut, Claudine and Howard Litwin (2015) Comparaison de l'entraide familiale à l'échelle européenne: idées reçues, réalités et incertitudes. Informations sociales 2(188), 54-63.

Attias-Donfut, Claudine, Jim Ogg and François-Charles Wolff (2005) European patterns of intergenerational financial and time transfers. European Journal of Ageing 2(3), 161-173.

Baeriswyl, Marie (2016) Participations et rôles sociaux à l'âge de la retraite: une analyse des évolutions et enjeux autour de la participation sociale et des rapports sociaux de sexe. Geneva, Switzerland: University of Geneva. https://archive-ouverte.unige.ch/unige:85309.

Bocklisch, Franziska, Steffen F. Bocklisch and Josef F. Krems (2012) Sometimes, often, and always: exploring the vague meanings of frequency expressions. Behavior Research Methods 44(1), 144-157.

Bourdieu, Pierre (1986) The forms of capital. In John G. Richardson (ed.), Handbook of Theory and Research for the Sociology of Education, pp. 241-258. New York, NY: Greenwood Press.

Broese van Groenou, Marjolain I. and Theo G. van Tilburg (2007) Network analysis. In James E. Birren (ed.), Encyclopedia of Gerontology: Age, Aging and the Aged, pp. 242-250. New York, NY: Elsevier.

Brückner, Hannah and Karl U. Mayer (2005) De-standardization of the life course: what it might mean? And if it means anything, whether it actually took place? Advances in Life Course Research 9, 27-53.

Buchmann, Marlis C. and Irene Kriesi (2011) Transition to adulthood in Europe. Annual Review of Sociology 37, 481-503.

Burt, Ronald S. (2001) The social capital of structural holes. In Mauro F. Guillén, Randall Collins, Paula England and Marshall Meyer (eds.), New Directions in Economic Sociology, pp. 148-192. New York, NY: Russell Sage Foundation.

Castrén, Anna-Maija and Kaisa Ketokivi (2015) Studying the complex dynamics of family relationships: a figurational approach. Sociological Research Online 20(1), 108-121.

Coleman, James S. (1988) Social capital in the creation of human capital. American Journal of Sociology 94, S95-S120.

Connidis, Ingrid A. (2015) Exploring ambivalence in family ties: progress and prospects. Journal of Marriage and Family 77(1), 77-95. 
Cornwell, Benjamin (2009a) Good health and the bridging of structural holes. Social Networks 31(1), 92-103.

Cornwell, Benjamin (2009b) Network bridging potential in later life: life-course experiences and social network position. Journal of Aging and Health 21(1), 129-154.

Cornwell, Benjamin (2011) Independence through social networks: bridging potential among older women and men. The Journals of Gerontology: Series B 66B(6), 782-794.

D’Andrade, Roy (1995) The Development of Cognitive Anthropology. Cambridge, UK: Cambridge University Press.

Elias, Norbert (1991) Qu'est-ce que la Sociologie? La Tour-d'Aigues, France: Editions de l'Aube.

Esping-Andersen, Gosta (1990) The Three Worlds of Welfare Capitalism. Princeton, NJ: Princeton University Press.

Ferrera, Maurizio (1996) Modèles de solidarité, divergences, convergences: perspectives pour l'Europe. Swiss Political Science Review 2(1), 1-18.

Gabriel, Rainer, Michel Oris, Matthias Studer and Marie Baeriswyl (2015) The persistence of social stratification? A life course perspective on old-age poverty in Switzerland. Swiss Journal of Sociology 41(3), 465-487.

Girardin, Myriam (2017) Les configurations familiales aux dernières étapes de la vie. Geneva, Switzerland: University of Geneva. https://doi.org/10.13097/archive-ouverte/unige:92688.

Girardin, Myriam and Eric D. Widmer (2015) Lay definitions of family and social capital in later life. Personal Relationships 22(4), 712-737.

Girardin, Myriam, Eric D. Widmer, Ingrid A. Connidis, Anna-Maija Castrén, Rita Gouveia and Barbara Masotti (2018) Ambivalence in later-life family networks: beyond intergenerational dyads. Journal of Marriage and Family 80(3), 768-784.

Granovetter, Mark S. (1973) The strength of weak ties. American Journal of Sociology 78(6), 1360-1380.

Hanneman, Robert A. and Mark Riddle (2005) Introduction to Social Network Methods. Riverside, CA: University of California, Riverside.

Kohli, Martin (1999) Private and public transfers between generations: linking the family and the state. European Societies 1(1), 81-104.

Kohli, Martin (2004) Intergenerational transfers and inheritance: a comparative view. In Merril Silverstein (ed.), Intergenerational Relations Across Time and Place (Annual Review of Gerontology \& Geriatrics: Vol. 24), pp. 266-289. New York, NY: Springer.

Kohli, Martin and Marco Albertini (2008) The family as a source of support for adult children's own family projects: European varieties. In Chiara Saraceno (ed.), Families, Ageing and Social Policy: Intergenerational Solidarity in European Welfare States, pp. 38-58. Cheltenham, UK: Edward Elgar Publishing.

Kohli, Martin and Harald Künemund (2003) Intergenerational transfers in the family: what motivates giving? In Vern L. Bengtson and Ariela Lowenstein (eds.), Global Aging and Challenges to Families, pp. 123-142. New York, NY: Aldine de Gruyter.

Künemund, Harald, Andreas Motel-Klingebiel and Martin Kohli (2005) Do intergenerational transfers from elderly parents increase social inequality among their middle-aged children? Evidence from the German aging survey. The Journals of Gerontology: Series B 60(1), S30-S36.

Le Goff, Maëlan, Julien Navaux and Lionel Ragot (2017) The impact of life stages on parent-child transfers. In Arnaud Régnier-Loilier (ed.), A Longitudinal Approach to Family Trajectories in France: The Generations and Gender Survey, pp. 199-215. New York, NY: Springer International Publishing.

Leopold, Thomas and Marcel Raab (2011) Short-term reciprocity in late parent-child relationships. Journal of Marriage and Family 73(1), 105-119.

Lüscher, Kurt and Karl Pillemer (1998) Intergenerational ambivalence: a new approach to the study of parent-child relations in later life. Journal of Marriage and Family 60(2), 413-425.

Merluzzi, Jennifer and Ronald S. Burt (2013) How many names are enough? Identifying network effects with the least set of listed contacts. Social Networks 35(3), 331-337.

Oris, Michel, Rainer Gabriel, Gilbert Ritschard and Matthias Kliegel (2017) Long lives and old age poverty: social stratification and life-course institutionalization in Switzerland. Research in Human Development 14(1), 68-87.

Oris, Michel, Eduardo Guichard, Marthe Nicolet, Rainer Gabriel, Aude Tholomier, Christophe Monnot, Delphine Fagot and Dominique Joye (2016) Representation of vulnerability and the elderly. A total 
survey error perspective on the VLV survey. In Michel Oris, Caroline Roberts, Dominique Joye and Michèle Ernst-Stähli (eds.), Surveying Human Vulnerabilities Across the Life Course, pp. 27-64. New York, NY: Springer International Publishing.

Silverstein, Merril, Xuan Chen and Kenneth Heller (1996) Too much of a good thing? Intergenerational social support and the psychological well-being of older parents. Journal of Marriage and the Family 58(4), 970-982.

Silverstein, Merril, Daphna Gans and Frances M. Yang (2006) Intergenerational support to aging parents: the role of norms and needs. Journal of Family Issues 27(8), 1068-1084.

StataCorp (2011) Stata 12 Survey Data Reference Manual. College Station (Tex.): Stata Press.

Suitor, J. Jill, Karl Pillemer and Jori Sechrist (2006) Within-family differences in mothers' support to adult children. The Journals of Gerontology: Series B 61B(1), S10-S17.

Swartz, Teresa T. (2009) Intergenerational family relations in adulthood: patterns, variations, and implications in the contemporary United States. Annual Review of Sociology 35, 191-212.

Szydlik, Marc (2016) Sharing Lives: Adult Children and Parents. New York, NY: Routledge.

Thoits, Peggy A. (2011) Mechanisms linking social ties and support to physical and mental health. Journal of Health and Social Behavior 52(2), 145-161.

van Gaalen, Ruben I. and Pearl A. Dykstra (2006) Solidarity and conflict between adult children and parents: a latent class analysis. Journal of Marriage and Family 68(4), 947-960.

Wasserman, Stanley and Katherine Faust (1994) Social Network Analysis: Methods and Applications. Cambridge, UK: Cambridge University Press.

Widmer, Eric D. (1999) Family contexts as cognitive networks: a structural approach of family relationships. Personal Relationships 6(4), 487-503.

Widmer, Eric D. (2006) Who are my family members? Bridging and binding social capital in family configurations. Journal of Social and Personal Relationships 23(6), 979-998.

Widmer, Eric D. (2016) Family Configurations: A Structural Approach to Family Diversity. London, UK: Routledge.

Widmer, Eric D., Gaëlle Aeby and Marlène Sapin (2013) Collecting family network data. International Review of Sociology 23(1), 27-46.

Widmer, Eric D., Myriam Girardin and Catherine Ludwig (2018) Conflict structures in family networks of older adults and their relationship with health-related quality of life. Journal of Family Issues 39(6), 1573-1597.

Widmer, Eric D. and Ritta Jallinoja (eds.) (2008) Beyond the Nuclear Family: Families in a Configurational Perspective. Bern: Peter Lang.

Zelizer, Viviane A. (2017) The Social Meaning of Money. Princeton, NJ: Princeton University Press.

Cite this article: Baeriswyl M, Girardin M, Oris M (2022). Financial support by older adults to family members: a configurational perspective. Journal of Demographic Economics 88, 167-194. https://doi.org/ $10.1017 / \mathrm{dem} .2021 .21$ 